\title{
Generalidades de la producción de embriones bovinos in vitro
}

\section{Overview of the production of bovine embryos in vitro}

\author{
Panorâmica da produção de embriões \\ bovinos in vitro
}

\begin{abstract}
Ángela María Gonella Diaza', Jorge Eduardo Atuesta Bustos², Sandra Milena Bernal Ulloa ${ }^{3}$ \& Liliana Chacón Jaramillo ${ }^{4}$

${ }^{1}$ Médica Veterinaria Zootecnista, Magister en Salud Animal. 2Zootecnista, Magister en Producción Animal. ${ }^{3}$ Médica Veterinaria Zootecnista, Especialista en Reproducción Bovina Tropical y T.E., Magister en Animal Sciences, Estudiante Doctorado en Veterinary Research and Animal Biology en University of Veterinary Medicine Hannover, Alemania. ${ }^{4}$ Médica Veterinario,

Magister en Salud y Producción Animal, Doctora en Salud y Producción Animal ${ }^{1}$ Grupo de Investigación en Nutrición, Toxicología y Reproducción Animal. Universidad Cooperativa de Colombia. Bucaramanga, Colombia. ${ }^{2}$ Escuela de Ciencias Agrícolas, Pecuarias y del Medio Ambiente (ECAPMA), Universidad Nacional Abierta y a Distancia (UNAD). Bogotá, Colombia. ${ }^{3}$ Facultad de Ciencias Pecuarias. Universidad de Ciencias Aplicadas y Ambientales, UDCA. Bogotá, Colombia.

${ }^{4}$ Facultad de Ciencias Agropecuarias. Universidad de la Salle. Bogotá, Colombia.
\end{abstract}

1angela.gonella@campusucc.edu.co, 2iorge.atuesta@unad.edu.co, 3sabernalu@udca.edu.co, ${ }^{4}$ Ichacon@unisalle.edu.co

\section{Resumen}

La producción de embriones in vitro (PIV) es una biotecnología reproductiva que impacta los sistemas ganaderos favoreciendo el mejoramiento genético y que también se ha utilizado como modelo de investigación del desarrollo embrionario en otras especies. Para el desarrollo de ésta técnica, se colectan oocitos in vivo por medio de laparoscopia y aspiración folicular guiada por ultrasonografía ó a través de ovarios recolectados en plantas de sacrificio. Los oocitos son sometidos a procesos de maduración in vitro, utilizando diversos medios, adición de gonadotropinas y factores de crecimiento. Los espermatozoides son sometidos a tratamientos de capacitación espermática in vitro, donde adquieren capacidad fertilizante y se separan los espermatozoides vivos de los componentes seminales y crio- protectores. Para la fertilización in vitro se realiza un cocultivo de espermatozoides y oocitos en un medio que favorece la actividad espermática y penetración de la zona pelúcida. Posteriormente, los embriones obtenidos son sometidos a cultivo en medios que contengan fuentes de energía, aminoácidos y factores de crecimiento, con el fin de mantener su sobrevivencia y desarrollo. En la actualidad la técnica de PIV en bovinos se ha masificado y se trabaja en los procesos de estandarización en otras especies. A partir de la PIV se dio el desarrollo de nuevas biotecnologías como la clonación y transgénesis. El objetivo de esta revisión es describir las fases de la PIV y su relación con los eventos fisiológicos de la fertilización y desarrollo embrionario temprano.

Palabras clave: biotecnología, desarrollo embrionario, espermatozoides, fertilización, oocitos. 


\section{Abstract}

In vitro embryo production (IEP) is a reproductive biotechnology that impacts livestock systems favoring breeding and which have also been utilized as research models for embryo development in other species. For the development of this method, oocytes in vivo are collected through laparoscopy and ultrasound guided follicular aspiration, or through ovaries collected from slaughterhouses. The oocytes are subjected to maturation processes in vitro using various culture media, addition of gonadotropins and growth factors. Spermatozoids undergo in vitro sperm capacitacion process, where fertilization capacity is adquired and live spermatozoids are separated from the seminal components and Cryoprotectants. The oocyte-sperm co-culture for the in vitro fertilization is carried out in a media that promotes maximum sperm activity and zona pellucida penetration. For in vitro fertilization is carried out in a medium favorable to sperm activity and pellucid zone penetration. Subsequently, the collected embryos are subjected to culture media that contain energy sources, amino acids and growth factors in order to maintain their survival and development. Currently, IEP in cattle has become large-scale and is working on standardization process for other species. Through PIV, biotechnologies such as cloning and transgenesis have been developed. The aim of this review is to describe the PIV phases and their relation with the physiological events of fertilization and early embryo development.

Key-words: biotechnology, embryonic development, spermatozoids, fertilization, oocytes.

\section{Resumo}

A produção in vitro de embriões (PIV) é uma biotecnologia reprodutiva com efeitos nos sistemas de criação de gado favorecendo o melhoramento genético e também tem sido usada como um modelo de pesquisa do desenvolvimento embrionário em outras espécies. Para o desenvolvimento desta técnica, são coletados ovócitos in vivo via laparoscopica: Para o desenvolvimento desta técnica,são coletados ovócitos in vivo por laparoscopiaou aspiração folicular por ultrassonografia ou atravésde ovários colhidos em abatedouro. Os ovócitos são submetidos a processos de maturação in vitro, utilizando-se vários meios, adição de gonadotrofinas e fatores de crescimento. Os espermatozóides são submetidos a tratamento na capacitação espermática in vitro, onde adquirem a capacidade de fertilização e são separados os espermatozoides vivos dos componentes seminais e crioprotetores. Para a fertilização in vitro é utilizada uma co-cultura de espermatozoides e ovócitos num meio que promove a atividade espermática e a penetração na zona pelúcida. Subsequentemente, os embriões são submetidos à cultura em meios contendo fontes de energia, aminoácidos e fatores de crescimento, a fim de manter a sua sobrevivência $e$ crescimento. Na atualidade a técnica PIV em bovinos é massificada e se trabalha em processos de padronização em outras espécies. A partir do PIV foi dado o desenvolvimento de novas biotecnologias, como a clonagem e transgênese. O objetivo desta revisão é descrever as fases da PIV e sua relação com os eventos fisiológicos da fecundação e desenvolvimento embrionário inicial.

Palavras-chave: biotecnologia, desenvolvimento embrionário, espermatozoides, fecundação, ovócitos. 


\section{Introducción}

La producción de embriones in vitro (PIV) es una biotecnología reproductiva que tiene un gran potencial como herramienta en el mejoramiento genético porque permite un acortamiento del intervalo generacional y logra aumentar la propagación del material genético en los hatos (Gonçalves, et al., 2001; Camargo et al., 2006; Rodríguez-Martinez, 2012). Además, se han venido utilizando a los embriones bovinos como modelos para la investigación de procesos metabólicos, genéticos y del desarrollo de embriones de otras especies, incluso la especie humana (Leidenfrost et al., 2011). Este potencial ha favorecido el uso masivo y comercial de la técnica durante la última década. El número de embriones bovinos producidos in vitro y transferidos alrededor del mundo, pasó de 42.000 anuales, a casi 300.000 en los últimos 10 años, siendo Brasil el país con la mayor producción a nivel mundial (Block et al., 2011). La PIV involucra las etapas de colecta, maduración (MIV) y fertilización (FIV) de oocitos, y el cultivo embrionario (CIV) como tal (Gonçalves, et al., 2001). La PIV es una biotecnología utilizada alternativamente para acelerar la producción de animales genéticamente superiores y para impedir, por medio de la aspiración in vivo de folículos, el descarte precoz de hembras genéticamente privilegiadas portadoras de alteraciones adquiridas (no transmisibles genéticamente a su descendencia) que impidan que la reproducción ocurra de forma natural (Hasler, 1993; Looney et al., 1994).

Alrededor de 1920, se iniciaron los ensayos de cultivar embriones de animales domésticos en especial de conejos. En los años 50 se registró el nacimiento del primer conejo a través de una FIV (Chang, 1955). En cuanto a bovinos, se iniciaron trabajos de MIV y FIV al final de la década de los setenta, registrándose el primer nacimiento a principios de los años ochenta (Brackett et al., 1982). La PIV en bovinos recibió gran impulso en los ochenta por comprobarse su viabilidad en condiciones artificiales. Debido al gran potencial de aplicación que la PIV presenta en animales y humanos, se difundió ampliamente en muchos países a partir de los años noventa (Gonçalves, et al., 2001). En la actualidad se trabaja (en explotaciones comerciales bovinas) con un $25-40 \%$ de producción de blastocitos (Pontes et al., 2011). El objetivo de esta revisión es proporcionar un enfoque que integre las diferentes fases involucradas en la técnica de PIV y su relación con los eventos fisiológicos de la fertilización y el desarrollo embrionario temprano.

\section{Colecta de oocitos}

Se estima que una hembra bovina al nacimiento puede contener aproximadamente 75,000 oocitos en cada uno de sus ovarios. Sin embargo, únicamente se obtienen entre 4 a 5 crías durante su vida adulta (Asdell, 1955). Demostrándose así, que se está sub-utilizando una hembra con alto valor genético cuando se utiliza la monta natural y la inseminación artificial (IA) (Smeaton et al., 2003). Por lo tanto, estos miles de oocitos inmaduros pueden ser aprovechados antes de que un animal de alta calidad genética sea descartado y producir embriones.

El oocito es el gameto que contribuye con la mitad del genoma embrionario y prácticamente la totalidad del citoplasma del cigoto, brindándole los organelos, proteínas y demás componentes celulares que necesita para su desarrollo temprano (Armstrong, 2001; Fair et al., 2007). El oocito debe ser competente para completar su meiosis y convertirse en una célula haploide, prepararse citoplasmáticamente para la fertilización, reprogramar la cromatina del espermatozoide y su propia cromatina, de manera que se formen los dos pronúcleos funcionales, dirigir el desarrollo embrionario temprano e inducir la activación genómica del embrión (Hamatani et al., 2008). Es por esto que una óptima calidad de los oocitos es indispensable para obtener buenos resultados en los procesos de PIV (Camargo et al., 2006; Leibfried-Rutledge, 1999). Rizos et al., (2005) aseguran que la calidad de los oocitos llevados a MIV es el principal factor que afecta los resultados obtenidos en esta técnica. 
El estado (clínico y fisiológico) de las hembras donadoras (Rizos et al., 2005), el tamaño folicular (Sirard, 2011) y la integridad de las células del cumulus (Leibfried-Rutledge, 1999; Armstrong, 2001) son factores que afectan la calidad del oocito.

El crecimiento del oocito dentro del folículo es un proceso lento que tarda aproximadamente 6 meses en bovinos (Lussier et al., 1987; Camargo et al., 2006). Durante este proceso adquiere la competencia meiótica por la interacción que se establece entre éste, las células de la teca y las células de la granulosa; y acumula enzimas, RNA, proteínas y otras moléculas importantes, que intervendrán más adelante en los procesos de maduración, fertilización y desarrollo embrionario. La acumulación de estos compuestos es de vital importancia debido a que se requerirán durante los primeros estadios del posterior desarrollo embrionario (Camargo et al., 2006; Ferreira et al., 2009). Durante ésta etapa las células embrionarias no tienen la capacidad de realizar procesos de transcripción de DNA (Mamo et al., 2011). Es por esto que, oocitos provenientes de folículos muy pequeños ( $<2-5 \mathrm{~mm}$ ) poseen menores tasas de MIV, FIV y producción de blastocitos que los oocitos provenientes de folículos de mayor tamaño ( $>5 \mathrm{~mm}$ ). Esto puede deberse a que el oocito aún no ha alcanzado su capacitación meiótica y/o maduración citoplasmática o porque estos folículos ya pueden estar iniciando un proceso de atresia (Lonergan et al., 1994; Leibfried-Rutledge, 1999; Ferreira et al., 2009), lo que demuestra la evidente relación entre el tamaño folicular y la calidad y subsiguiente desarrollo del oocito bajo condiciones in vitro (Sirard, 2011). El número de folículos antrales que se encuentran en los ovarios de un individuo en un momento determinado depende de: la movilización de reservas del ovario, el desarrollo folicular en sus fases iniciales (que a su vez depende del estado metabólico, endocrinológico y nutricional del individuo) y la dinámica de crecimiento durante la fase antral (Viana \& Bols, 2005; Sirard, 2011).

Los primeros intentos para obtener oocitos de los folículos directamente del ovario, se realizaron en humanos utilizando la aspiración folicular guiada por ultrasonido conocida como ovum pick up - OPU (Gleicher et al., 1983; Dellenbach et al., 1984). Posteriormente esta técnica fue adaptada en bovinos también llamada aspiración transvaginal - TVR (transvaginal recovery), (Pieterse et al., 1988; Pieterse et al., 1991). Según la frecuencia de las aspiraciones, la edad del animal, razas y otros factores se pueden obtener entre 50 a 100 gestaciones al año cuando se utilizan los oocitos de una sola vaca (Bols, 1997).

Los oocitos bovinos pueden ser obtenidos in vivo mediante las técnicas de aspiración folicular guiada con ultrasonido, laparoscopia vía flanco o por laparotomía ventral o medial (Gordon, 1994; Bols, 2001). La laparotomía fue la primera técnica utilizada para estos fines pero fue desplazada rápidamente debido a su naturaleza invasiva y laboriosa. Esta tiene grandes inconvenientes como: la anestesia general, la necesidad de médico veterinario cirujano, con ciertas instalaciones y equipo, más de un operario para su ejecución, además de las complicaciones inherentes a toda cirugía (Bols, 2001); sin embargo en la actualidad se continúa utilizando esta técnica en casos específicos como en la recuperación de oocitos en animales prepúberes, que al ser de bajo peso y talla no pueden ser aspirados con el ultrasonido transvaginal (Taneja et al., 2000; Bernal et al., 2011). La laparoscopia fue adoptada alrededor de la década de 1980 (Sirard \& Lambert, 1985; Sirard et al., 1985; Sirard et al., 1985a). A pesar de ser considerada una técnica con un alto grado de repetibilidad, la visualización del ovario suele ser complicada y requiere de personas expertas para realizar la recolección debido al riesgo de presentar adherencias en el sitio de la punción y de peritonitis (Bols, 2001). La OPU fue desarrollada en la década de los 80 con el fin de recolectar los oocitos de una manera menos traumática que la cirugía o la laparoscopia (Callesen et al., 1987; Pieterse et al., 1991). Entre sus principales ventajas se encuentra que es menos invasiva y su posible aplicación sin el uso indispensable del estímulo hormonal, aunque se debe tener en cuenta que se obtiene un mayor número de folículos con 
estimulación previa (Pontes et al., 2011), la posibilidad de ser utilizada en cualquier momento del ciclo estral incluso en estados de gestación temprana (Viana \& Bols, 2005). Además, es bastante rápida y el operador requiere una asistencia mínima (Bols, 1997; Viana \& Bols, 2005; Pontes et al., 2011). En la actualidad es la técnica más utilizada para la PIV ya sea con propósitos comerciales o de investigación, incluso cuando se trabaja con donadoras de alto potencial genético (Pontes et al., 2011).

Otra valiosa fuente de oocitos son los ovarios de vacas faenadas, recolectados en plantas de sacrificio. Estos constituyen una buena fuente para la investigación y la producción, cuando no se requiere de animales genéticamente privilegiados (Gonçalves, et al., 2001; Palma, 2001), como la producción en masa. Pero también cuando se conoce un lote de animales que van a ser sacrificados y se reconoce su mérito genético (recuperación genética, "beef from dairy"), o se debe hacer "fusil" sanitario por la presencia de una enfermedad en una región o país (Galli et al., 2003). Sin embargo, es conocido que este material es extremadamente heterogéneo en términos de calidad y desarrollo in vitro (Lonergan et al., 1994). Dichos ovarios pueden ser sometidos a procesos de disección o punción folicular. Normalmente son transportados en solución salina al $0.9 \%$ de $\mathrm{NaCl}$ a una temperatura que oscila entre los 30 y $35^{\circ} \mathrm{C}$ (Gonçalves, et al., 2001; Palma, 2001). En el laboratorio los ovarios son lavados con solución salina, suero fisiológico, alcohol y en algunos casos con antibióticos (Penicilina y estreptomicina los más comunes) (Gonçalves, et al., 2001). La punción folicular se realiza con agujas de calibre 18 o mayor, y con bisel corto tanto in vivo como en piezas faenadas (Gonçalves, et al., 2001).

\section{Los sistemas de cultivo celular}

Existen varias clases de medios de cultivos para oocitos y embriones, los cuales tratan de simular los nutrientes encontrados en el tracto reproductivo, por lo tanto se han basado en los estudios realizados sobre la composición de diferentes electrólitos, carbohidratos, lípidos, aminoácidos y proteínas entre otros (Miller \& Schultz, 1987; Thompson, 1996; Holm et al., 1999). Sin embargo, se establece generalmente la siguiente clasificación, de acuerdo a sus formulaciones (Farin et al., 2001; Camargo et al., 2006):

Medios Indefinidos: contienen suero fetal bovino o co-cultivo con células somáticas. El suero fetal bovino (SFB) proporciona varios nutrientes a los embriones como aminoácidos, vitaminas, factores de crecimiento, y sustratos energéticos (Thompson et al., 1998; Rizos et al., 2003; Leivas et al., 2011). Sin embargo, puede contaminar el medio de cultivo con factores embriotóxicos (Gonçalves, et al., 2001). Aunque se ha demostrado que el SFB aumenta significativamente el porcentaje de obtención de blastocitos (Leivas et al., 2011), varios estudios muestran que el suero tiene un efecto "bifásico" sobre los embriones, inhibiendo las divisiones celulares tempranas pero acelerando el desarrollo hacia estadios más avanzados (Abe et al., 2002; Wrenzycki et al., 2004). Los embriones producidos con adición de SFB al medio pueden presentar alteraciones ultra estructurales, defectos en la compactación y la blastulación, perfiles de expresión genética anormales y mayor incidencia del síndrome del ternero grande (Abe et al., 2002; Wrenzycki et al., 2004). Así mismo, debido a que el SFB también aumenta la acumulación de lípidos citoplasmáticos, se reduce la supervivencia embrionaria cuando se realizan procesos de criopreservación (Camargo et al., 2006; Rizos et al., 2003; Abe et al., 2002). Los co-cultivos con células somáticas, también pueden ser usados en los medios indefinidos. Estas pueden contribuir al desarrollo embrionario al remover sustancias nocivas (como metales pesados) y radicales libres del medio de CIV, además de secretar factores de crecimiento (Gordon, 1994). Las células somáticas pueden variar severamente los resultados obtenidos en los sistemas de PIV, aumentando significativamente la variabilidad individual al usar diversos tipos de células o de diversos animales (Rizos et al., 2002). 
Medios Semidefinidos: son medios donde no hay co-cultivos y el SFB es remplazado con albúmina sérica bovina (BSA: por sus siglas en inglés) (Palma, 2001). Esta contribuye con la eliminación de algunos componentes potencialmente dañinos del suero (Palma, 2001). La albúmina es una de las proteínas con mayor presencia en el tracto reproductivo de los mamíferos y se cree que tiene un importante papel en la nutrición del embrión durante su desarrollo en las fases de post-compactación (Camargo et al., 2006); A pesar que su rol exacto en este proceso todavía no es totalmente claro, se cree que sirve de sustrato de aminoácidos a los embriones en crecimiento (Camargo et al., 2006; Gordon, 1994). En diversos estudios se ha demostrado que la BSA logra mejores tasas de criopreservación embrionaria comparada con el SFB (Rizos et al., 2002; Räty et al., 2011) sin embargo, la BSA es también un componente biológico sujeto a posible contaminación que puede causar fallas graves durante la maduración del oocito y el desarrollo embrionario (Thompson \& Peterson, 2000).

Medios Definidos: Son sistemas libres de proteínas, donde la BSA es remplazada por macromoléculas como el polivinil alcohol y polivinilpirrolidona (Camargo et al., 2006). La ventaja de estos sistemas es que los efectos nocivos del SFB, el co-cultivo y la BSA son eliminados, sin embargo hasta hoy, no se han obtenido las mismas tasas de blastocitos transferibles, preñeces y terneros nacidos vivos que con los medios indefinidos o semidefinidos (Camargo et al., 2006). Es por esto que su uso comercial es aun limitado y continua la investigación en su búsqueda (Camargo et al., 2006).

\section{Maduración de oocitos in vitro (MIV)}

El oocito, al interior del folículo, está envuelto por células de la granulosa, formando el complejo $\mathrm{Cu}$ mulus-Oocito (COC) (Asdell, 1955; Sirard, 2011). El conjunto de células próximas a la zona pelúcida que están en íntimo contacto con el oocito por uniones intercomunicantes, se denominan corona radiada.
Esas células del cumulus tienen función diferenciada de aquellas presentes en la pared del folículo, en consecuencia de su contacto directo con el oocito (Callejas, 2001). Sustancias reguladoras producidas por el oocito cumplen una función importante en la actividad de las células del cumulus y de la misma manera, componentes de estas células somáticas tienen participación activa en los mecanismos de maduración y crecimiento del oocito (Fair et al., 2007; Krisher, 2004; Haccard \& Jessus, 2006).

Las características microscópicas del folículo son importantes para determinar el potencial de maduración nuclear y citoplasmática del oocito. Los oocitos presentes en folículos menores de $2 \mathrm{~mm}$ de diámetro, generalmente no son competentes para reiniciar la meiosis, mientras que un elevado porcentaje de folículos mayores de $8 \mathrm{~mm}$ ya están en proceso de atresia (Gordon, 1994). Morfológicamente, los oocitos con mayor viabilidad deben presentar citoplasma homogéneo con granulaciones finas, de coloración marrón y completamente envueltos por varias capas de células del cumulus dispuestas en forma compacta (Krisher, 2004). Varias clasificaciones morfológicas han sido adoptadas para seleccionar oocitos bovinos con el objetivo de identificar los de mayor viabilidad (Gonçalves, et al., 2001). La más común es la que los separa en una escala de valores de 1 a 4 , considerando las características del cumulus y del citoplasma del oocito (Leibfried \& First, 1979):

Calidad 1: cumulus compacto presente, conteniendo más de tres capas de células. Citoplasma con granulaciones finas y homogéneas, zona pelúcida llena, completa y de coloración marrón.

Calidad 2: cumulus compacto parcialmente presente con menos de 3 capas de células. Citoplasma con granulaciones distribuidas heterogéneamente, pudiendo estar más concentradas en el centro y más distribuidas en la periferia o condensadas en una sola zona aparentando una mancha oscura.

Calidad 3: cumulus presente, pero expandido. Citoplasma contraído con espacio entre la membrana 
celular y la zona pelúcida, degenerado, vacuolizado o fragmentado.

Calidad 4: oocito desnudo sin células del cumulus

El oocito presente en el folículo primordial, una vez activado, debe crecer y sufrir varias modificaciones de orden ultra estructural, citoesquelético y bioquímico con la finalidad de tornarse competente para reiniciar y completar la maduración meiótica (Ptak et al., 1999; Salamone et al., 2001). Los oocitos competentes reinician in vivo, la primera división meiótica coincidentemente luego del pico ovulatorio de LH (Leibfried-Rutledge, 1999; Gonçalves, et al., 2001; Palma, 2001). La maduración del oocito está ligada a una serie de transformaciones estructurales y bioquímicas que hacen que el gameto femenino sea apto para ser fecundado y alcanzar el desarrollo embrionario subsiguiente (Leibfried-Rutledge, 1999; Gonçalves, et al., 2001; Palma, 2001). La maduración del oocito ocurre a nivel nuclear y citoplasmático (Ptak et al., 1999). La maduración citoplasmática se refiere al proceso que prepara al oocito para la activación, formación de los pro-núcleos y el desarrollo en la fase de pre-implantación (Ledda et al., 1999; Ptak et al., 1999; Salamone et al., 2001). Al iniciar el proceso de maduración, la trascripción de genes necesarios para la síntesis de proteínas durante el inicio del desarrollo embrionario disminuye casi por completo (Lonergan et al., 1994; Mamo et al., 2011). La modulación de la síntesis proteica es observada simultáneamente con la reorganización de organelos citoplasmáticos (Lonergan et al., 1994), reportándose variaciones en su número, tamaño y posición (Damiani et al., 1996; Ledda et al., 1999; Mamo et al., 2011). En la restructuración citoplasmática, la mayoría de los organelos migran hacia el centro de la célula a excepción de los gránulos corticales que van hacia la periferia ooplásmica y adquieren la capacidad de realizar exocitosis (Fair et al., 2007; Mamo et al., 2011).

Las principales modificaciones bioquímicas del ooplasma incluyen: aumento en la actividad de la proteína kinasa activadora mitogénica (MAPK) y del factor promotor de maduración (MPF), el desarrollo de los mecanismos controladores del aumento de $\mathrm{Ca}^{+}$y la capacidad de descondensar la cromatina del esperma fertilizante (Salamone et al., 2001; Haccard \& Jessus, 2006). El MPF se considera como el regulador universal del ciclo celular tanto para los procesos de meiosis como para los de mitosis (Haccard \& Jessus, 2006). La MAPK y el MPF se activan luego de un largo proceso que aún no se comprende en su totalidad, durante el reinicio de la meiosis y hasta su segundo arresto. Por lo que bajos niveles de estos factores o su inapropiada activación pueden influir seriamente en la capacidad de desarrollo de los oocitos (Salamone et al., 2001).

Por otra parte, el proceso de maduración nuclear del oocito bovino requiere de 18 a 22 horas y comprende el reinicio de la meiosis desde la profase meiótica de la primera división hasta la metafase II (segunda división) (Lonergan et al., 1994; Ptak et al., 1999; Salamone et al., 2001). Este proceso se restablece de manera correcta si el oocito cuenta con una competencia meiótica (Guimarães, 2000). Esta competencia se adquiere progresivamente durante el crecimiento folicular y del oocito; y es asociada con una serie de cambios nucleares y del ooplasma. Los principales eventos nucleares son la ruptura de la vesícula germinal, la condensación de los cromosomas, el avance hasta la metafase I, la expulsión del primer cuerpo polar y el subsiguiente segundo arresto meiótico en la metafase II hasta la fertilización (Guimarães, 2000; Salamone et al., 2001).

Durante la maduración nuclear y citoplasmática las células somáticas que envuelven el oocito también sufren significativas modificaciones (Leibfried-Rutledge, 1999; Gonçalves, et al., 2001). Se ha sugerido que el "diámetro crítico" al cual los oocitos adquieren la capacidad de desarrollarse es de 110-120 $\mu \mathrm{m}$, diámetro que corresponde con folículos de más de $3 \mathrm{~mm}$ (Fair et al., 1995; Duby et al., 1996; Fair, 2003; Viana \& Bols, 2005). Después de la maduración, los oocitos son mantenidos en Metafase II hasta la fecundación o la activación partenogenética (Lonergan et al., 1994). 
Una gran cantidad de medios han sido utilizados para la MIV sin embargo, en la actualidad la mayoría de equipos utiliza como medio base el TCM199 con sales de EARLE (Camargo et al., 2006). Este medio es modificado conforme la rutina de cada laboratorio. En relación a las hormonas, es usual la utilización de LH, FSH o la combinación de las dos (Keefer et al., 1993; Gordon, 1994; Choi et al., 2001). La adición de SFB al medio de MIV ha sido sugerida como un requisito para alcanzar una óptima expansión del cumulus y la maduración del oocito. Además del medio, otros factores relacionados con el ambiente de cultivo celular deben ser considerados como fundamentales para el desarrollo embrionario. Para esto, es necesaria una incubadora que mantenga una atmósfera gaseosa y temperatura constantes. Generalmente la MIV de oocitos bovinos es realizada a $39^{\circ} \mathrm{C}$ por 22 a 24 horas en atmósfera de $5 \%$ de $\mathrm{CO}_{2}$ (Gordon, 1994; Oyamada \& Fukui, 2004; Bermejo-Alvarez et al., 2010).

No solo las gonadotropinas juegan un importante papel en regulación intraovárica. Se ha demostrado la presencia de factores de crecimiento como IGF 1, VEGF y MPF en fluido y células foliculares y se han identificado varios de sus receptores, lo que sugiere que estas moléculas toman parte en el crecimiento folicular y el proceso de maduración del oocito (Haccard \& Jessus, 2006; Fair et al., 2007), razón por la cual se han venido agregando a diversos medios de MIV (Oropeza et al., 2004).

\section{Capacitación espermática}

El espermatozoide es funcionalmente inmaduro, infértil e inmóvil mientras permanece en el testículo, y adquiere la capacidad de fecundar en el epidídimo (Alberts, 1996; Eddy, 2006). La mayor parte de los cambios que ocurren en el epidídimo están relacionados con la adquisición de motilidad y en menor grado con la morfología y el metabolismo (Alberts, 1996; Eddy, 2006). La maduración es un reflejo de muchas variaciones bioquímicas del espermatozoide como la estabilización de cromatina y de las estructuras de cabeza y cola, estabilización de la membrana plasmática por la absorción e integración de glicoproteínas epididimarias, adquisición de movimientos progresivos y habilidad para ligarse a la zona pelúcida (Alberts, 1996; Darzon et al., 1999; Eddy, 2006). Los espermatozoides, en contacto con el plasma seminal, sufren incorporaciones y modificaciones de factores decapacitantes en su superficie que los hacen incapaces de fecundar. Este fenómeno bioquímico es denominado decapacitación espermática (Darzon et al., 1999). La capacitación espermática es de fundamental importancia para que estos espermatozoides se tornen aptos para fecundar in vivo, este proceso ocurre en el tracto genital de la hembra por la remoción de los factores decapacitantes debido a las interacciones que se establecen entre el espermatozoide y los factores capacitantes. Dicha interacción no produce modificaciones morfológicas pero si bioquímicas, que resultan en desestabilización y fluidez de la membrana plasmática y la hiperactivación espermática, esenciales para que ocurra la reacción del acrosoma y la posterior penetración del espermatozoide en el oocito (Alberts, 1996). Esta capacidad se desencadena a partir de la eyaculación en el tracto genital femenino y en el curso de la migración espermática, razón por la cual depende del ciclo estral y de las condiciones útero-tubáricas que condicionan el transporte y viabilidad de las células espermáticas (Alberts, 1996; Eddy, 2006). En la presencia de calcio extracelular, el espermatozoide capacitado tiene la habilidad de ligarse a la zona pelúcida del oocito y de sufrir la reacción acrosómica. Esta reacción envuelve la segmentación progresiva del acrosoma y la fusión de las membranas plasmática (oocito) y acrosómica (espermatozoide), formando vesículas y permitiendo la liberación de enzimas y la exposición de la membrana interna (Darzon et al., 1999; Mayorga et al., 2007; Hu et al., 2010).

Los mecanismos de capacitación espermática aún no están bien definidos, pero se reconoce 
que algunos glucosaminoglicanos presentes en el tracto genital femenino son los responsables de la eliminación de componentes adheridos a la membrana del espermatozoide, alteración de la composición lipídica de su membrana, aumento de la permeabilidad de los iones de $\mathrm{Ca}^{+}$, cambios en el $\mathrm{pH}$ intracelular y un aumento del metabolismo (Alberts, 1996; Darzon et al., 1999; Eddy, 2006). Los glucosaminoglicanos son polímeros lineales constituidos por la sucesión de unidades estructurales disacáridas formadas generalmente por un ácido urónico y una hexosamina (Palma, 2001). En el proceso in vitro, la heparina es el glucosaminoglicano mas extensamente utilizado para capacitar los espermatozoides bovinos.

Existe variación individual entre toros, en cuanto a la concentración de heparina necesaria para la capacitación espermática, sin embargo, la concentración ideal de heparina varía de 2 a $100 \mu \mathrm{g} /$ $\mathrm{ml}$ de medio (Gordon, 1994a). Otras sustancias han sido utilizadas en los medios para realizar el proceso de capacitación in vitro, como la catecolamina, adrenalina y el aminoácido hipotaurina, con lo cuales se ha encontrado un notable aumento en la motilidad espermática y la penetración del oocito (Miller et al., 1994; Palma, 2001).

\section{Preparación espermática para la FIV}

Las técnicas más utilizadas para la separación de espermatozoides vivos, de los demás componentes seminales y de los crioprotectores son el "swim up", los gradientes de percoll y el lavado espermático (Palma, 2001). Idealmente, la separación de los espermatozoides debe ser simple, rápida, de bajo costo, donde se logre el procesamiento de grandes volúmenes de semen, controlando la concentración y volumen final de la suspensión espermática. Además, no debe provocarse ninguna alteración espermática durante el procesamiento y se deben recuperar la mayoría de espermatozoides motiles removiendo componentes indeseables como los espermatozoides muertos, microorganismos, sustancias toxicas y bioactivas (Gonçalves, et al., 2001).

En el protocolo "swim up", los espermatozoides vivos son separados de los muertos, del plasma seminal y de los componentes diluyentes, por la motilidad ascendente (Parrish \& Foote, 1987; Parrish et al., 1995). Ese proceso consiste en depositar de 200 a $500 \mu \mathrm{l}$ de semen en el fondo de tubos de centrifuga que contengan entre 1 y $2 \mathrm{ml}$ del medio sperm-talp, para que el semen permanezca en el fondo del tubo, cubierto por este. En seguida estos tubos son incubados en una atmósfera de $5 \%$ de $\mathrm{CO}_{2}$ y a una temperatura entre 39 y $45^{\circ} \mathrm{C}$ durante una hora, permitiendo que los espermatozoides migren hacia la posición superior del medio y que los demás constituyentes del semen permanezcan en el fondo del tubo (Gordon, 1994a; Parrish \& Foote, 1987). En una segunda etapa, el sobrenadante es aspirado, de tal forma que no permita que los componentes del fondo del tubo entren en contacto con los espermatozoides. En seguida se transfiere esta porción a otro tubo con el fin de centrifugarla y se le adicionan $4 \mathrm{ml}$ del medio sperm-talp (Gordon, 1994a; Parrish et al., 1995). Por último se centrifuga nuevamente para obtener una concentración final de 1 a 2 x10 espermatozoides/ml (Palma, 2001).

En la técnica del Percoll, el semen se centrifuga, pasándolo por diferentes gradientes de concentración, para permitir la separación de los espermatozoides vivos de los demás constituyentes del semen, basándose en la diferencia de densidades (Parrish et al., 1995). Para la dilución del percoll, el medio sperm-talp tendrá sus sales concentradas en una proporción de 10 veces. Con ese medio, se prepara una solución de percoll al $90 \%$, y luego se realiza una segunda dilución de percoll a $45 \%$. En el fondo del tubo se coloca primero la solución de percoll $90 \%$ y luego, muy lentamente, se coloca la misma cantidad de percoll $45 \%$, sin permitir que las dos soluciones se mezclen. El contenido de la pajilla de semen se deposita a la superficie, y esto se somete a centrifugación por 
30 minutos. Al terminar la centrifugación, el pellet resultante alberga a los espermatozoides vivos, y todo el sobrenadante es descartado (Gonçalves, et al., 2001; Somfai et al., 2002; Samardzija et al., 2006).

\section{Fertilización in vitro de oocitos (FIV)}

Luego de terminar la MIV y de tener separados los espermatozoides viables, se debe proporcionar un ambiente apto para que ocurra la capacitación espermática y la fecundación (Gonçalves, et al., 2001). Dicho ambiente debe permitir el correcto metabolismo de las células del cumulus y del oocito y mantener la función espermática eficiente. Para esto, el medio más utilizado es el FERT, que contiene heparina para la capacitación espermática. El co-cultivo (espermatozoides-oocitos) es realizado por un período ente 18 y 22 horas, a una temperatura de $39^{\circ} \mathrm{C}$, en una atmósfera de $5 \%$ de $\mathrm{CO}_{2}$ (Palma, 2001). De igual forma, en algunos laboratorios se suele adicionar PHE (penicilamina, hipotaurina, epinefrina), al medio FERT, con el fin de aumentar la actividad espermática y de facilitar su penetración, incrementando los índices de fecundación (Miller et al., 1994).

El espermatozoide penetra en la zona pelúcida por acciones enzimáticas y mecánicas (Brewis \& Wong, 1999; Leibfried-Rutledge, 1999; Florman \& Ducibella, 2006). La reacción acrosómica permite liberación de enzimas que digieren la matriz de la zona pelúcida (Brewis \& Wong, 1999; Florman \& Ducibella, 2006). La fusión del oocito con el espermatozoide ocurre después de la penetración, específicamente por el contacto entre el segmento ecuatorial del espermatozoide y la membrana plasmática del oocito (Alberts, 1996). El oocito activado por el espermatozoide responde inicialmente con la despolarización de la membrana plasmática, aumento de las oscilaciones intracelulares de calcio, exocitosis de los gránulos corticales, aumento del $\mathrm{pH}$ intracelular y la síntesis proteica (Alberts, 1996; Brewis \& Wong, 1999; Darzon et al., 1999). Para impedir la penetración de más de un espermatozoide, ocurre el bloqueo primario de la poliespermia que se debe a la rápida despolarización de la membrana plasmática del oocito después de la fecundación, denominado bloqueo vitelínico (Gonçalves, et al., 2001; Florman \& Ducibella, 2006). Luego de la penetración ocurre la segunda división meiótica y los cromosomas que permanecen en el oocito son introducidos a una membrana nuclear, formando el pronúcleo femenino. De la misma forma, la membrana nuclear del espermatozoide se desintegra, la cromatina nuclear se descondensa por la remoción de proteínas nucleares específicas y ocurre la formación de una nueva membrana nuclear que envuelve los cromosomas paternos, formando el pronúcleo paterno mitótica (Brewis \& Wong, 1999; Florman \& Ducibella, 2006). Durante su desarrollo, los pronúcleos femenino y masculino migran para el centro del ooplasma, allí ocurre la singamia donde los pronúcleos se desintegran y los cromosomas se asocian para la primera división mitótica (Alberts, 1996; Florman \& Ducibella, 2006). Una vez completado el proceso de fecundación los cromosomas paternos y maternos se asocian dando inicio al desarrollo embrionario, el cual ya cuenta con un genoma nuevo.

\section{Cultivo de embriones in vitro (CIV)}

Luego de finalizar la etapa de fertilización in vitro, los oocitos fertilizados son sometidos a la etapa de cultivo. El objetivo de esta etapa es permitir que, los oocitos fertilizados se desarrollen hasta un estadio embrionario en el que se pueda realizar la transferencia a la receptora.

Aunque la glucosa es la principal fuente de energía consumida por las células embrionarias, se ha demostrado que posee efectos perjudiciales en el desarrollo temprano de embriones mamíferos como el aumento de las concentraciones de radicales libres intracelulares (Leibfried-Rutledge, 1999; Camargo et al., 2006), por esta razón, el piruvato y el lactato son las fuentes de energía elegidas preferentemente en 
los medios de CIV (Takahashi \& First, 1999; Wirtu et al., 2003; Karja et al., 2004). La tensión de oxigeno que la mayoría de embriones mamíferos encuentra en el tracto reproductivo es de 3.5 a $8 \%$, debido a esto los embriones deben ser cultivados in vitro usando una tensión de oxigeno similar (Takahashi \& First, 1999; Wirtu et al., 2003; Karja et al., 2004). Los beneficios de una baja tensión de oxígeno en los medios de CIV son diversos, entre estos se pueden encontrar: un incremento en el número de células, una mejor tasa de producción de embriones y una menor producción de radicales libres (Gordon, 1994a; Takahashi \& First, 1999) mientras que, una tensión de oxigeno mayor al 5\% puede causar apoptosis de las células embrionarias y/o alterar el patrón de expresión génica, en parte por la mayor concentración intracelular de radicales libres (Camargo et al., 2006). Estos intervienen en el metabolismo celular impidiendo su replicación y por ende, disminuyendo su tasa de crecimiento. Viana et al., 2005 utilizaron la adición de óxido nítrico al medio de CIV para disminuir la formación de radicales libres, aumentando la obtención de blastocitos.

Las secreciones del tracto reproductivo de la hembra presentan una gran cantidad de aminoácidos que pueden ser utilizados por el embrión como fuente energética y para la síntesis de proteínas (Miller \& Schultz, 1987; Wirtu et al., 2003). Por tal razón, el uso de aminoácidos en medios de CIV libres de suero aumenta el desarrollo embrionario, probablemente debido a su acción antioxidante y el control que ejercen sobre el pH (Takahashi \& First, 1999). Sin embargo, la utilización de aminoácidos incrementa las concentraciones de amonio dentro del medio, razón por la cual este debe ser remplazado cada tres días (Takahashi \& First, 1999).

Se ha demostrado que los factores de crecimiento secretados por las células somáticas, estimulan el crecimiento de los embriones mamíferos (Block et al., 2007; Block et al., 2011). El factor de crecimiento epidermal (EGF), mejora la maduración nuclear y la tasa de clivaje, así como el desarrollo embrionario (Lim et al., 2007). El factor de crecimiento similar a la insulina tipo 1 (IGF-1), incrementa la tasa de blastocitos y el número de células al estimular la mitosis embrionaria (Block et al., 2007; Block et al., 2011). De igual manera, se han encontrado receptores para la hormona de crecimiento y el IGF-1 en células de cumulus, oocitos y embriones (Oropeza et al., 2004).

Al finalizar el proceso de singamia, se origina el cigoto con un nuevo arreglo citoplasmático y se da inicio a la formación de un organismo multicelular con un nuevo potencial genético (proveniente de padre y madre). En esta fase ocurren una serie de divisiones mitóticas por medio de las cuales, el cigoto que posee una sola célula de gran volumen, se divide en numerosas células de menor tamaño. Los estadios de desarrollo embrionario inicialmente se nombran de acuerdo al número de células que posee el embrión (2, 4, 8, 16, 32 y 64 células), hasta que se convierte en mórula, en la cual, las blastómeras se agrupan en una masa sólida en la que no se distinguen correctamente cada una de las células (Brackett et al., 1982; Gonçalves, et al., 2001; Thompson \& Peterson, 2000). En los mamíferos, el genoma embrionario comienza su trascripción desde las fases iniciales del desarrollo y es común que estas divisiones iniciales ocurran de manera muy lenta, por lo que suelen encontrarse embriones con número impar de células (Latham et al., 2002). Siendo esta otra característica del desarrollo temprano, ya que las primeras divisiones suelen ser asíncronas, o sea que los blastómeros no se dividen simultáneamente (Latham et al., 2002). Luego que se ha dado la formación de la mórula, comienzan a diferenciarse en el embrión dos tipos celulares: las células de la masa celular interna, que darán origen a el feto y las células del embrioblasto que darán origen a una parte del corion y estarán en contacto directo con el útero materno luego de la eclosión y durante la implantación (Alberts, 1996).

En los animales domésticos ocurre un fenómeno de compactación de las blastómeras, las cuales parecen perder sus identidades y formar una única 
masa celular ( $\mathrm{MCl}$ : masa celular interna) (Florman \& Ducibella, 2006). Este fenómeno de compactación es esencial para que posteriormente se formen el trofoblasto y el embrioblasto constituyéndose así, la primera diferenciación celular en embriones mamíferos (Peippo et al., 2011). En bovinos y ovinos esta compactación ocurre en el estadio de 32 células.

Los primeros eventos que ocurren con el embrión son marcados por la diferenciación de las uniones entre los blastómeros, con la formación de las uniones incipientes firmes y las uniones de tipo gap (Latham et al., 2002; Peippo et al., 2011). La diferenciación de células embrionarias en células del trofoblasto o en células del embrioblasto es determinada por sus posiciones en la fase de mórula es decir, las células del interior de la mórula van a dar origen al embrioblasto, mientras que las de la periferia, darán origen al trofoblasto (Florman \& Ducibella, 2006). La formación del blastocele (cavidad del blastocisto) es una etapa que sucede luego de la compactación del embrión, que en este estadio se conoce como mórula compacta (Palma, 2001). Para la formación del blastocele, es necesario que se incremente la cantidad de fluido que pasa a través de las células del trofoblasto hacia el interior del embrión. Luego de la formación del blastocisto ocurre su expansión, en consecuencia del continuo acumulo de líquido y de la división celular. Durante la expansión del blastocisto, la asincronía de la división celular aumenta y sucede de forma más lenta (Latham et al., 2002; Peippo et al., 2011).

\section{Conclusiones y perspectivas}

La PIV se ha masificado en la última década de manera significativa. A pesar que los bovinos continúan siendo la especie donde más se utiliza esta biotecnología, se han logrado dar grandes avances en la aplicación comercial de esta técnica en ovinos y caprinos. En otras especies como los equinos, porcinos, caninos y felinos, se han logrado registrar nacimientos e incluso hacer avances importantes en la estandarización de las condiciones de los medios de cultivo sin embargo, aún no se dispone masivamente de estos procesos a nivel comercial y generalmente se realizan con fines de investigación. La mayoría de laboratorios trabajan para optimizar los medios de cultivo, de manera que se asemejen al máximo a las condiciones naturales del oviducto y útero materno. Esto permitirá en un futuro producir embriones que sean más resistentes a los procedimientos de transferencia, criopreservación y micromanipulación.

A partir de la PIV se dio inicio el desarrollo de nuevas biotecnologías como la clonación, la micromanipulación de embriones, la inyección intracitoplasmática de espermatozoides (ICSI), la utilización de las células madres embrionarias y la transgénesis. Procedimientos de ICSI se realizan rutinariamente en las clínicas de reproducción asistida en parejas con problemas de infertilidad. Igualmente, se han logrado grandes avances en la producción de animales transgénicos como cerdos, salmones, cabras, ovejas y vacas. Generalmente, la finalidad de estos transgenes es la producción a gran escala de proteínas, enzimas, hormonas, etc. que al ser fabricadas de manera sintética resultan muy costosas. La clonación de individuos, a pesar de haber generado una gran cantidad de críticas y debates, se encuentra disponible comercialmente para bovinos en países como Brasil, Argentina y Estados Unidos, entre otros. Es de esperarse que, en el campo de la biotecnología, continúen los procesos de investigación que conlleven a avances importantes. Se podría esperar que estos procedimientos comenzaran a aplicarse de manera más frecuente e incluso, a estar disponibles comercialmente en los próximos años. Sin embargo, es evidente la necesidad de seguir profundizando en los procesos fisiológicos y moleculares que regulan el desarrollo embrionario, con el fin de manipularlos de una manera más certera y poder incrementar la tasa de eficiencia de esta biotecnología. 


\section{Literatura citada}

1. Abe, H., Yamashita, S., Satoh, T \& Hoshi, H. (2002). Accumulation of cytoplasmic lipid droplets in bovine embryos and cryotolerance of embryos developed in different culture systems using serum- free or serum-containing media. Molecular Reproduction and Development, 61(1), 57-66.

2. Alberts, B. (1996).Fertilización del huevo. En Alberts, B., Bray, D., Lewis, J. (Ed.), Biología molecular de la célula, $3^{\text {ra }}$ Edición. Barcelona: Omega Editores;

3. Armstrong, D.T. (2001). Effects of maternal age on oocyte developmental competence. Theriogenology, 55(6), 1303-1322.

4. Asdell, S.A. (1955). Cattle Fertility and Sterility, 1st ed. Toronto: Boston Lillie, Brown \& Company.

5. Bermejo-Alvarez, P., Lonergan, P., Rizos, D. \& Gutiérrez-Adan, A. (2010). Low oxygen tension during IVM improves bovine oocyte competence and enhances anaerobic glycolysis. Reproductive Biomedicine Online, 20(3), 341-349.

6. Bernal, S., Gonella-Diaza, A.M., Valbuena, D., Mendoza, R., Molina, J. \& Chacón, L. (2011). Effect of age and coasting period on oocytes quality and their in vitro development from prepubertal cattle. Revista MVZ Córdoba, 16(2),2499-2506.

7. Block, J. (2007). Use of insulin-like growth factor-1 to improve post-transfer survival of bovine embryos produced in vitro. Theriogenology, 68, Suppl 1, 49-55.

8. Block, J., Hansen, P.J., Loureiro, B. \& Bonilla, L. (2011). Improving post-transfer survival of bovine embryos produced in vitro: Actions of insulin-like growth factor-1, colony stimulating factor-2 and hyaluronan. Theriogenology, 76 (9), 1602-1609.

9. Bols, P.E.J. (1997). Transvaginal ovum pick-up in the cow: technical and biological modifications. PhD Thesis. Faculty of Veterinary Medicine, University of Ghent, Belgium, 227p.

10. Bols, P. (2001). Punction Folicular (Ovum Pick-Up, OPU) en la vaca. En: Palma GA, Editor. Biotecnología de la reproducción, 1ed. (pp.185-224). Buenos Aires: Balcacere.

11. Brackett, R.G., Bousquet, D., Boice, M.L., Donawick, W.J., Evans, J.F., et al. (1982). Normal development following in vitro fertilization in the cow. Biology of Reproduction, 27, 147-158.

12. Brewis, I.A. \& Wong, C.H. (1999). Gamete recognition: sperm proteins that interact with the egg zona pellucida. Reviews of Reproduction, 4(3), 135-142.

13. Callejas, S. (2001). Fisiología del ciclo estral Bovino. En: Palma GA, Editor. Biotecnología de la reproducción 1ed (pp. 37-59). Buenos Aires: Balcacere.

14. Callesen, H.T., Greve, T. \& Christensen, F. (1987). Ultrasonically guided aspiration of bovine follicular oocytes [Abstract]. Theriogenology, 27(1), 217.

15. Camargo, L.S.A., Viana, J.H.M., Sá, W.F., Ferreira, A.M., Ramos, A.A., et al. (2006). Factors influencing in vitro embryo production. Animal Reproduction, 3(1), 19-28.
16. Chang, M.C. (1955). The maturation of rabbit oocytes in the culture and their maturation, activation, fertilization, and subsequent development in the fallopian tubes. Journal of experimental zoology. Part A, Ecological genetics and physiology, 123, 379-386.

17. Choi, Y.H., Carnevale, E.M., Seidel, G.E. Jr. \& Squire, E.L. (2001). Effects of gonadotropins on bovine oocytes matured in TCM-199. Theriogenology, 56(4), 661-70.

18. Damiani, P., Fissore, R.A., Cibelli, J.B., Long, C.R., Balise, J.J., et al. (1996). Evaluation of developmental competence, nuclear and ooplasmic maturation of calf oocytes. Molecular Reproduction and Development, 45(4), 521-534.

19. Darzon, A., Labarca, P., Nishigaki, T. \& Espinosa, F. (1999). Ion channels in sperm physiology. Physiological Reviews, 79(2), 481-509.

20. Dellenbach, P., Nisand, I., Moreau, L., Feger, B., Plumere, C., et al. (1984). Transvaginal, sonographically controlled ovarian follicle puncture for egg retrieval. The Lancet, 323(8392), 1467.

21. Duby, R.T., Damiani, P., Looney, C.R., Fissore, R.S. \& Robl, J.M. (1996). Prepubertal calves as oocyte donors: promises and problems. Theriogenology, 49(1): 1077-1082.

22. Eddy, E.M. (2006). The Spermatozoon. En: Jimmy D. Neill et.al. (eds.)

23. K'nobil and Neill's Physiology of Reproduction. $3^{\text {rd }}$ Edition (pp. 3-54). USA: Elsevier academic press.

24. Fair, T. (2003). Follicular oocyte growth and acquisition of developmental competence. Animal Reproduction Science, 78(3-4), 203-216.

25. Fair, T., Carter, F., Park, S., Evans, A.C.O. \& Lonergan ,P. (2007). Global gene expression analysis during bovine oocyte in vitro maturation. Theriogenology, $68 \mathrm{Suppl}$ 1, S91-S97.

26. Fair, T., Hyttel, P. \& Greve, T. (1995). Bovine oocyte diameter in relation to maturational competence and transcriptional activity. Molecular Reproduction and Development ,42(4), 437-442.

27. Farin, P.W., Crosier, A.E. \& Farin, C.E. (2001). Influence of in vitro systems on embryo survival and fetal development in cattle. Theriogenology, 55(1), 151-170.

28. Ferreira, E.M., Vireque, A.A., Adona, P.R., Meirelles, F.V., Ferriani, R.A., et al. (2010). Cytoplasmic maturation of bovine oocytes: structural and biochemical modifications and acquisition of developmental competence [fe de erratas en Theriogenology, 73(8),1164]. Theriogenology. 2009, 71(5), 836-848.

29. Florman, H. \& Ducibella, T. (2006). Fertilization in mammals. En: Jimmy D. Neill et.al. (eds.). K'nobil and Neill's Physiology of Reproduction. $3^{\text {rd }}$ Edition (pp. 55-112). USA: Elsevier academic press.

30. Galli, C., Duchi, R., Crotti, G., Turini, P., Ponderato, N., et al. (2003). Bovine embryo technologies. Theriogenology, 59, 599-616.

31. Gleicher, N., Friberg, J., Fullan, N., Giglia, R., Mayden, K., et al. (1983). Egg retrieval for in vitro fertilization by sonographically controlled vaginal culdocentesis. The Lancet, 322 (8348), 508-509. 
32. Gonçalves, P.B.D., Visintin, J.A., Oliveira, M.A.L, Montagner, M.M. \& Costa, L.F.S. (2001). Produção in vitro de Embriões. En: Gonçalves, P.B.D., Figueiredo, J.R., Freitas, V.J.F. (Ed.), Biotecnias aplicadas á reprodução animal (pp. 195-226). São Paulo: Livraria Varela.

33. Gordon I. (1994). Oocyte recovery and maturation. En: Laboratory production of cattle embryos (pp 30-142). Wallingford, UK: CAB International.

34. Gordon I. (1994a). Capacitating Bovine Sperm. En: Laboratory production of cattle embryos $2^{\text {nd }}$ Edition (pp 158-176). Wallingford, UK: CAB International.

35. Guimarães, P. (2012). Genética Básica para Veterinaria. $3^{a}$ Edición. São Paulo: Roca.

36. Haccard, O. \& Jessus, C. (2006). Oocyte maturation, Mos and cyclins a matter of synthesis: two functionally redundant ways to induce meiotic maturation. Cell cycle, 5 (11), 1152-1159.

37. Hamatani, T., Yamada, M., Akutsu, H., Kuji, N., Mochimaru, Y., et al. (2008). What can we learn from gene expression profiling of mouse oocytes? Reproduction, $135,581-592$.

38. Hasler, J.F. (1993). Applications of in vitro fertilization technology to infertile dairy cows. En: Proceedings of the 12th Annual Convention American Embryo Transfer Association; Portland, Maine, USA.

39. Holm, P., Booth, P.J., Schmidt, M.H., Greve, T. \& Callesen, H. (1999). High bovine blastocyst development in a static in vitro production system using SOFaa medium supplemented with sodium citrate and myo-inositol with or without serum-proteins. Theriogenology, 52(4), 683-700.

40. Hu, X.Q., Ji, S.Y., Li, Y.C., Fan, C.H., Cai, H., et al. (2010). Acrosome formation-associated factor is involved in fertilization. Fertility and Sterility, 93(5),1482-1492.

41. Karja, N.W., Medvedev, S., Onishi, A., Fuchimoto, D., Iwamoto, M., et al. (2004). Effect of replacement of pyruvate/lactate in culture medium with glucose on preimplantation development of porcine embryos in vitro. Journal of Reproduction and Development, 50(5), 587-592.

42. Keefer, C.L., Stice, S.L. \& Dobrinsky, J. (1993). Effect of follicle-stimulating hormone and luteinizing hormone during bovine in vitro maturation on development following in vitro fertilization and nuclear transfer. Molecular Reproduction and Development, 36(4),469-74.

43. Krisher, R.L. (2004). The effect of oocyte quality on development. Journal of Animal Science, 82, E-Suppl, E14-E23

44. Latham, K.E., Akutsu, H., Patel, B. \& Yanagimachi, R. (2002). Comparison of gene expression during preimplantation development between diploid and haploid mouse embryos. Biology of Reproduction, 67(2), 386-392.

45. Ledda, S., Bogliolo, L., Leoni, G. \& Naitana, S. (1999). Production and Lambing rate of blastocysts derived from in vitro matured oocytes after gonadotropin treatment of prepubertal ewes. Journal of Animal Science, 77(8), 2234-2239.
46. Leibfried, L. \& First, N.L. (1979). Characterization of bovine follicular oocytes and their ability to mature in vitro. Journal of Animal Science, 48(1), 76-86.

47. Leibfried-Rutledge, M.L. (1999). Factors determining competence of in vitro produced cattle embryos. Theriogenology, 51(2), 473-485.

48. Leidenfrost, S., Boelhauve, M., Reichenbach, M., Güngör, T., Reichenbach, H.D., et al. (2011). Cell arrest and cell death in mammalian preimplantation development: lessons from the bovine model. PLoS One, 6(7), e22121.

49. Leivas, F.G., Brum, D.S., Fialho, S.S., Saliba, W.P., Alvim, M.T.T., et al. (2011). Fetal calf serum enhances in vitro production of Bos taurus indicus embryos. Theriogenology, 75(3), 429-433.

50. Lim, K.T., Jang, G., Ko, K.H., Lee, W.W., Park, H.J., et al. (2007). Improved in vitro bovine embryo development and increased efficiency in producing viable calves using defined media. Theriogenology, 67(2), 293-302.

51. Lonergan, P., Monaghan, P., Rizos, D., Boland, M.P. \& Gordon, I. (1994). Effect of follicle size on bovine oocyte quality and developmental competence following maturation, fertilization, and culture in vitro. Molecular Reproduction and Development, 37(1), 48-53.

52. Looney, C.R., Lindsey, B.R., Gonseth, C.L. \& Johnson, D.L. (1994). Commercial aspects of oocyte retrieval and in vitro fertilization (IVF) for embryo production in problem cows. Theriogenology, 41 (1), 67-72.

53. Lussier, J.G., Matton, P. \& Dufour, J.J. (1987). Growth rates of follicles in the ovary of the cow. Journal of Reproduction and Fertility, 81(2), 301-307.

54. Mamo, S., Carter, F., Lonergan, P., Leal, C.L.V., Al Naib, A., et al. (2011). Sequential analysis of global gene expression profiles in immature and in vitro matured bovine oocytes: potential molecular markers of oocyte maturation. BMC Genomics, 12, 151.

55. Mayorga, L.S., Tomes, C.N. \& Belmonte, S.A. (2007). Acrosomal exocytosis, a special type of regulated secretion. IUBMB Life, 59(4-5), 286-292.

56. Miller, G.F., Gliedt, D.W., Rakes, J.M. \& Rorie, R.W. (1994). Addition of penicillamine, hypotaurine and epinephrine (PHE) or bovine oviductal epithelial cells (BOEC) alone or in combination to bovine in vitro fertilization medium increases the subsequent embryo cleavage rate. Theriogenology, 41(3), 689-696

57. Miller, J.G.O. \& Schultz, G.A. (1987). Amino acid content of preimplantation rabbit embryos and fluids of the reproductive tract. Biology of Reproduction, 36(1), 125-129.

58. Oropeza, A., Wrenzycki, C., Herrmann, D., Hadeler, K.G. \& Niemann, H. (2004). Improvement of the developmental capacity of oocytes from prepubertal cattle by intraovarian Insulin-Like Growth Factor-I application. Biology of Reproduction, 70(6), 1634-1643.

59. Oyamada, T. \& Fukui, Y. (2004). Oxygen tension and medium supplements for in vitro maturation of bovine oocytes cultured individually in a chemically defined medium. Journal of Reproduction and Development, 50(1), 107-117. 
60. Palma GA. (2001). Producción in vitro de embriones bovinos. En: Palma GA, Editor. Biotecnología de la reproducción, 1ed (pp. 225-294). Buenos Aires: Balcacere.

61. Parrish, J.J., Foote, R.H. (1987). Quantification of bovine sperm separation by a swim-up method. Relationship to sperm motility, integrity of acrosomes, sperm migration in polyacrylamide gel and fertility. Journal of Andrology, 8(4), 259-266.

62. Parrish, J.J., Krogenaes, A. \& Susko-Parrish, J.L. (1995). Effect of bovine sperm separation by either swimup or Percoll method on success of in vitro fertilization and early embryonic development. Theriogenology, 44(6),859-69.

63. Peippo, J., Machaty, Z. \& Peter, A. (2011). Terminologies for the pre-attachment bovine embryo. Theriogenology, 76(8), 1373-1379.

64. Pieterse, M.C., Kappen, K.A., Kruip, T.A., Taverne, M.A. (1988). Aspiration of bovine oocytes during transvaginal ultrasound scanning of the ovaries. Theriogenology, 30(4), 751-762.

65. Pieterse, M.C, Vos, P.L., Kruip, A.M., Willemse, A.H., Taverne, M.A. (1991). Characteristics of bovine estrous cycles during repeated transvaginal ultrasound-guided puncturing of follicles for ovum pick-up. Theriogenology, 35(2), 401-413.

66. Pontes, J.H., Melo Sterza, F.A., Basso, A.C., Ferreira, C.R., Sanches, B.V., et al. (2011). Ovum pick up, in vitro embryo production, and pregnancy rates from a largescale commercial program using Nelore cattle (Bosindicus) donors. Theriogenology, 75(9), 1640-1646.

67. Ptak, G., Loi, P., Dattena, M., Tischner, M. \& Cappai, P. (1999). Offspring from one-month-old lambs: studies on the developmental capability of prepubertal oocytes. Biology of Reproduction, 61(6), 1568-1574.

68. Räty, M., Ketoja, E., Pitkänen, T., Ahola, V., Kananen, $\mathrm{K}$., et al. (2011). In vitro maturation supplements affect developmental competence of bovine cumulus-oocyte complexes and embryo quality after vitrification. Cryobiology, 63(3), 245-255.

69. Rizos, D., Burke, L., Duffy, P., Wade, M., Mee, J.F., et al. (2005). Comparisons between nulliparous heifers and cows as oocyte donors for embryo production in vitro. Theriogenology, 63(3), 939-949.

70. Rizos, D., Gutiérrez-Adán, A. \& Pérez-Garnelo, S., De La Fuente, J., Boland, M.P., et al. (2003). Bovine embryo culture in the presence or absence of serum: implications for blastocyst development, cryotolerance, and messenger RNA expression. Biology of Reproduction, 68(1), 236-243.

71. Rizos, D., Lonergan, P., Boland, M.P., Arroyo-García, R., Pintado, B., et al. (2002). Analysis of differential messenger RNA expression between bovine blastocysts produced in different culture systems: implications for blastocyst quality. Biology of Reproduction, 66(3), 589-595.
72. Rodriguez-Martinez, H. (2012). Assisted Reproductive Techniques for Cattle Breeding in Developing Countries: A Critical Appraisal of Their Value and Limitations. Reproduction in Domestic Animals. 47 Suppl(1), 21-26.

73. Salamone, D.F., Damiani, P., Fissore, R.A., Robl, J.M. \& Duby, R.T. (2001). Biochemical and developmental evidence that ooplasmic maturation of prepubertal bovine oocytes is compromised. Biology of Reproduction, 64(6), 1761-1768.

74. Samardzija, M., Karadjole, M., Matkovic, M., Cergolj, M., Getz, I., et al. (2006). A comparison of BoviPure and Percoll on bull sperm separation protocols for IVF. Animal Reproduction Science, 91(3-4),237-247.

75. Sirard, M.A. (2011). Follicle environment and quality of in vitro matured oocytes. Journal of Assisted Reproduction and Genetics, 28(6), 483-488.

76. Sirard, M.A. \& Lambert, R.D. (1985). In vitro fertilization of follicular oocytes obtained by laparoscopy. Biology of Reproduction, 33(2): 487-494.

77. Sirard, M.A., Lambert, R.D., Beland, R. \& Bernard, C. (1985). The effects of repeated laparoscopic surgery used for ovarian examination and follicular aspiration in cows. Animal Reproduction Science, 9(1), 25-30.

78. Sirard, M.A., Lambert, R.D., Guay, P., Menard, D.P. \& Bedoya, M. (1985a). In vivo and in vitro development of in vitro fertilized bovine follicular oocytes obtained by laparoscopy [Abstract]. Theriogenology, 23(1), 230.

79. Smeaton, DC., Harris, B.L., Xu, Z.Z. \& Vivanco, W.H. (2003). Factors affecting commercial application of embryo technologies in New Zealand: a modelling approach. Theriogenology 59(2): 617-634.

80. Somfai, T., Bodó, S., Nagy, S., Papp, A.B., Iváncsics, J., et al. (2002). Effect of swim up and Percoll treatment on viability and acrosome integrity of frozenthawed bull spermatozoa. Reproduction in Domestic Animals, 37(5),285-290.

81. Takahashi, Y. \& First, N.L. (1992). In vitro development of bovine one-cell embryos: Influence of glucose, lactate, pyruvate, amino acids and vitamins. Theriogenology, 37(5), 963-978.

82. Taneja, M., Bols, P., Van De Velde, A., Ju, J.C., Schreiber, D., et al. (2000). Developmental competence of juvenile calf oocytes in vitro and in vivo: influence of donor animal variation and repeated gonadotropin stimulation. Biology of Reproduction, 62(1), 206-213.

83. Thompson, J.G. (1996). Defining the requirements for bovine embryo culture. Theriogenology, 45(1), 27-40.

84. Thompson,J.G., Allen, N.W., McGowan, L.T., Bell, A.C. \& Lambert, M.G. (1998). Effect of delayed supplementation of fetal calf serum to culture medium on bovine embryo development in vitro and following transfer. Theriogenology, 49(6), 1239-1249.

85. Thompson, J.G. \& Peterson, A.J. (2000). Bovine embryo culture in vitro: new developments and post-transfer consequences. Human Reproduction. 15, Suppl (5), 59-67. 
86. Viana, J.H.M. \& Bols, P.E.J. (2005). Biologic variables associated with Cummulus oocyte Complex recovery using follicular aspiration. Acta Scientiae Veterinariae, 33 Suppl (1), 1-4.

87. Viana, K.S., Caldas-Bussiere, M.C., Matta, S.G.C., Paes De Carvalho, C.S. \& Faes, M.R., et al. (2005). Effect of nitric oxide addiction in bovine oocyte during maturation in vitro. Acta Scientiae Veterinariae,33 Suppl (1), 169.

88. Wirtu, G., Pope, C.E., Damiani, P., Miller, F., Dresser, B.L., et al. (2003). Development of in-vitro-derived bo- vine embryos in protein-free media: effects of amino acids, glucose, pyruvate, lactate, phosphate and osmotic pressure. Reproduction Fertility and Development, 15(7-8), 439-449.

89. Wrenzycki, C., Herrmann, D., Lucas-Hahn, A., Lemme, E., Korsawe, K., et al.(2004). Gene expression patterns in in vitro-produced and somatic nuclear transfer-derived preimplantation bovine embryos: relationship to the large offspring syndrome? Animal Reproduction Science. 82-83, 593-603. 